\title{
Translating Surface-Initiated Atom Transfer Radical Polymerization into Technology: The Mechanism of Cu0-Mediated SI-ATRP under Environmental Conditions
}

\author{
Journal Article \\ Author(s): \\ Yan, Wenqing; Fantin, Marco; Spencer, Nicholas D.; Matyjaszewski, Krzysztof; Benetti, Edmondo M. \\ Publication date: \\ 2019-07-16 \\ Permanent link: \\ https://doi.org/10.3929/ethz-b-000357228 \\ Rights / license: \\ Creative Commons Attribution-NonCommercial 4.0 International \\ Originally published in: \\ ACS Macro Letters 8(7), https://doi.org/10.1021/acsmacrolett.9b00388 \\ Funding acknowledgement: \\ 669562 - Polymer Analogs to Biolubrication Systems: Novel materials for exploring cartilage tribology and exploiting its \\ mechanisms (EC) \\ 148156 - Polyoxazoline-Based Coatings On Polymeric Scaffolds Directing Tissue Regeneration (SNF)
}




\section{Translating Surface-Initiated Atom Transfer}

Radical Polymerization into Technology: The

\section{Mechanism of $\mathrm{Cu}^{0}$-Mediated SI-ATRP under}

\section{Environmental Conditions}

Wenqing Yan, ${ }^{1}$ Marco Fantin, ${ }^{2}$ Nicholas D. Spencer ${ }^{*}$

Krzysztof Matyjaszewski, ${ }^{2 *}$ Edmondo M. Benetti ${ }^{1,3 *}$

${ }^{1}$ Laboratory of Surface Science and Technology, Department of Materials, Swiss Federal Institute of Technology (ETH Zürich), Vladimir-Prelog-Weg 1-5/10, CH-8093 Zurich, Switzerland

${ }^{2}$ Department of Chemistry, Carnegie Mellon University, 4400 Fifth Avenue, Pittsburgh, PA 15213, USA

${ }^{3}$ Swiss Federal Laboratories for Materials Science and Technology (EMPA), Lerchenfeldstrasse 5, CH-9014, St. Gallen, Switzerland 


\section{Abstract}

The exceptional features of $\mathrm{Cu}^{0}$-mediated surface-initiated atom transfer radical polymerization $\left(\mathrm{Cu}^{0}\right.$ SI-ATRP), and its potential for implementation in technologically relevant surface functionalizations are clearly demonstrated thanks to a comprehensive understanding of its mechanism. $\mathrm{Cu}^{0}$ SI-ATRP enables the synthesis of multifunctional polymer brushes with a remarkable degree of control, over extremely large areas and without the need for inert atmosphere or deoxygenation of monomer solutions. When a polymerization mixture is placed between a flat copper plate and an ATRP-initiator-functionalized substrate, the vertical distance between these two overlaying surfaces determines the tolerance of the grafting process towards the oxygen, while the composition of the polymerization solution emerges as the critical parameter regulating polymer-grafting kinetics. At very small distances between the copper plate and the initiating surfaces, the oxygen dissolved in the solution is rapidly consumed via oxidation of the metallic substrate. In the presence of ligand, copper species diffuse to the surface-immobilized initiators and trigger a rapid growth of polymer brushes. Concurrently, the presence and concentration of added $\mathrm{Cu}^{\mathrm{II}}$ regulates the generation of $\mathrm{Cu}^{\mathrm{I}}$-based activators through comproportionation with $\mathrm{Cu}^{0}$. Hence, under oxygen-tolerant conditions, the extent of comproportionation, together with the solvent-dependent rate constant of activation ( $\mathrm{k}_{\mathrm{act}}$ ) of ATRP are the main determinants of the growth rate of polymer brushes. 
The interest in setting up robust methods for the controlled synthesis of polymer brushes by surface-initiated "living" polymerization techniques under environmental conditions has been recently rising. ${ }^{1-4}$

Focusing on the most widely applied of such methods, surface-initiated atom transfer radical polymerization (SI-ATRP), ${ }^{5}$ the reaction mixtures typically require careful degassing prior to incubation on initiator-bearing supports, while the polymerization vessels need to be either appropriately sealed, or under oxygen-free conditions during the entire duration of the grafting process. Moreover, the technical difficulties in performing SI-ATRP with large reaction volumes, while maintaining the system under fully inert conditions, hamper the fabrication of polymer brushes from large substrates. Hence, it is clear that an approach that could overcome these major drawbacks would tremendously broaden the applicability of SI-ATRP and, more generally, of "grafted-from" polymer brushes in technologically relevant fabrications.

Previously reported oxygen-tolerant SI-ATRP processes have involved the application of reducing agents, which simultaneously consume oxygen and generate catalytically active $\mathrm{Cu}^{\mathrm{I}-}$ based species. ${ }^{6-12}$ Photo-active compounds were also recently applied as oxygen scavengers and polymerization catalysts for metal-free SI-ATRP, enabling the synthesis of microstructured brushes under ambient conditions, with excellent temporal and spatial control. $^{13}$

An alternative, highly efficient approach to circumventing the need for deoxygenation relies on the use of zerovalent copper, $\mathrm{Cu}^{0}$, which acts as a source of active catalyst, ${ }^{14,}{ }^{15}$ simultaneously consuming dissolved oxygen when the polymerization mixture is not directly exposed to air. ${ }^{16,17}$

Although the robustness of $\mathrm{Cu}^{0}$-mediated SI-ATRP for the synthesis of multifunctional, gradient and microstructured polymer brushes has been already proven through the seminal 
works of Jordan et al. ${ }^{18-20}$ and also by several authors of the present work, ${ }^{21,22}$ little has been revealed about the mechanism of this grafting process, and its tolerance to oxygen.

By gaining a comprehensive understanding of the $\mathrm{Cu}^{0}$ SI-ATRP mechanism, in this work we demonstrate that the highly controlled growth of compositionally different brushes can be achieved from large substrates, without the need for deoxygenation of monomer mixtures or inert environments. In other words, a polymer grafting process through controlled/“living" radical polymerization can be readily performed on a benchtop, and translated into technology.

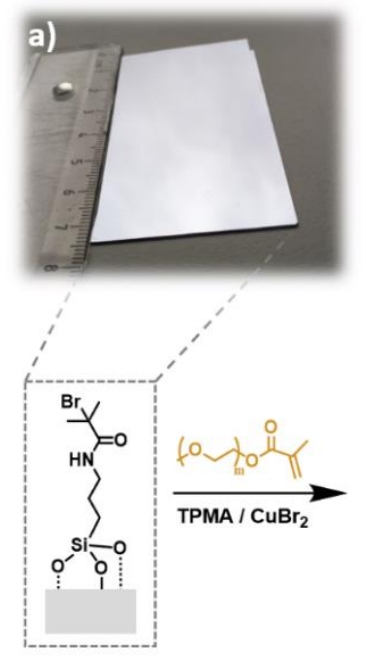

b)

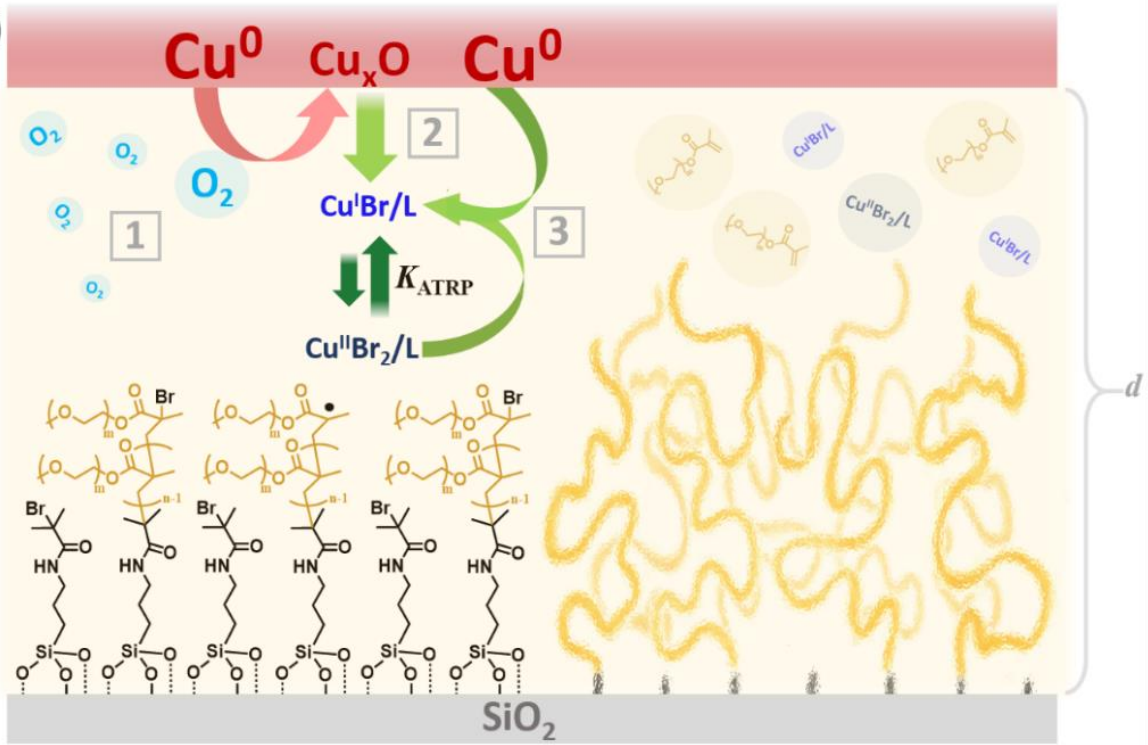

Scheme 1. (a) A polymerization mixture comprising monomer (OEGMA), ligand (TPMA) and $\mathrm{CuBr}_{2}$ is sandwiched between an ATRP-initiator-functionalized $\mathrm{SiO}_{2}$ substrate, and a copper plate. (b) The copper surface consumes oxygen dissolved in the polymerization mixture (1), and acts as source of $\mathrm{Cu}^{\mathrm{I}}$-based activators and $\mathrm{Cu}^{\mathrm{II}}$-based deactivators (2), which in the presence of ligand diffuse to the initiator-bearing surface, regulating the polymerization. Moreover, $\mathrm{Cu}^{0}$ participates in the comproportionation equilibrium (3), providing additional activators.

When a polymerization mixture is placed between a flat $\mathrm{Cu}^{0}$-coated plate and an ATRP initiator-functionalized substrate (Scheme 1 and Figure S1), the metallic surface first consumes oxygen within the polymerization mixture, generating an oxide layer that acts as source of both $\mathrm{Cu}^{\mathrm{I}}$ activator and $\mathrm{Cu}^{\mathrm{II}}$-based deactivator species. In the presence of ligand $(\mathrm{L})$, activators 
$(\mathrm{CuBr} / \mathrm{L})$ and deactivators $\left(\mathrm{CuBr}_{2} / \mathrm{L}\right)$ diffuse through the reaction medium, reaching the initiator-bearing substrate and triggering polymerization, which proceeds according to the ATRP equilibrium. It is also significant that the exposed $\mathrm{Cu}^{0}$ surface further acts as a reducing agent for $\mathrm{Cu}^{\mathrm{II}}$ species, generating $\mathrm{Cu}^{\mathrm{I}}$-based activators via comproportionation. ${ }^{14}$

The growths of poly(oligo(ethylene glycol) methacrylate) (POEGMA) and poly(methyl methacrylate) (PMMA) brushes, monitored ex situ by variable-angle spectroscopic ellipsometry (VASE), provide exemplary cases of $\mathrm{Cu}^{0}$ SI-ATRP performed under ambient conditions (Figure 1a and 1b). Significantly, neither the monomers nor the solvent were deoxygenated prior to polymerization, while the reaction mixture was simply poured on a $\mathrm{Cu}^{0}$ coated silicon wafer and immediately covered with a $30 \mathrm{~cm}^{2}$ initiator-functionalized $\mathrm{SiO}_{2}$ substrate, onto which a pressure of $3 \mathrm{~g} \mathrm{~cm}^{-2}$ was applied, by means of a weight (Figure 1c).

The vertical spacing $(d)$ between the copper plate and ATRP initiator-bearing substrates (Scheme 1), and the presence and concentration of added $\mathrm{Cu}^{\mathrm{II}}$ species, emerge as critical parameters regulating the synthesis of polymer brushes.

Under the experimental conditions applied, the reaction volume between the sandwiching surfaces corresponded to $1 \mu \mathrm{L} \mathrm{cm}^{-2}$, and $d \sim 10 \mu \mathrm{m}$. When the grafting process was performed in dimethyl sulfoxide (DMSO), and using tris(2-pyridylmethyl)amine (TPMA) as ligand, POEGMA and PMMA brushes reached $91 \pm 3$ and $36 \pm 4 \mathrm{~nm}$ of dry thickness, respectively, after 60 minutes of polymerization. In both cases, no induction period was observed. This is consistent with the average diffusion path lengths calculated from the Einstein equation (Supporting Information), which suggest that less than 1 second was necessary for activators to reach the initiator-bearing surface. Moreover, the virtually instantaneous polymer-brush growth indicates that the consumption of oxygen was rapid within the small reaction volumes existing between the two opposing surfaces. 

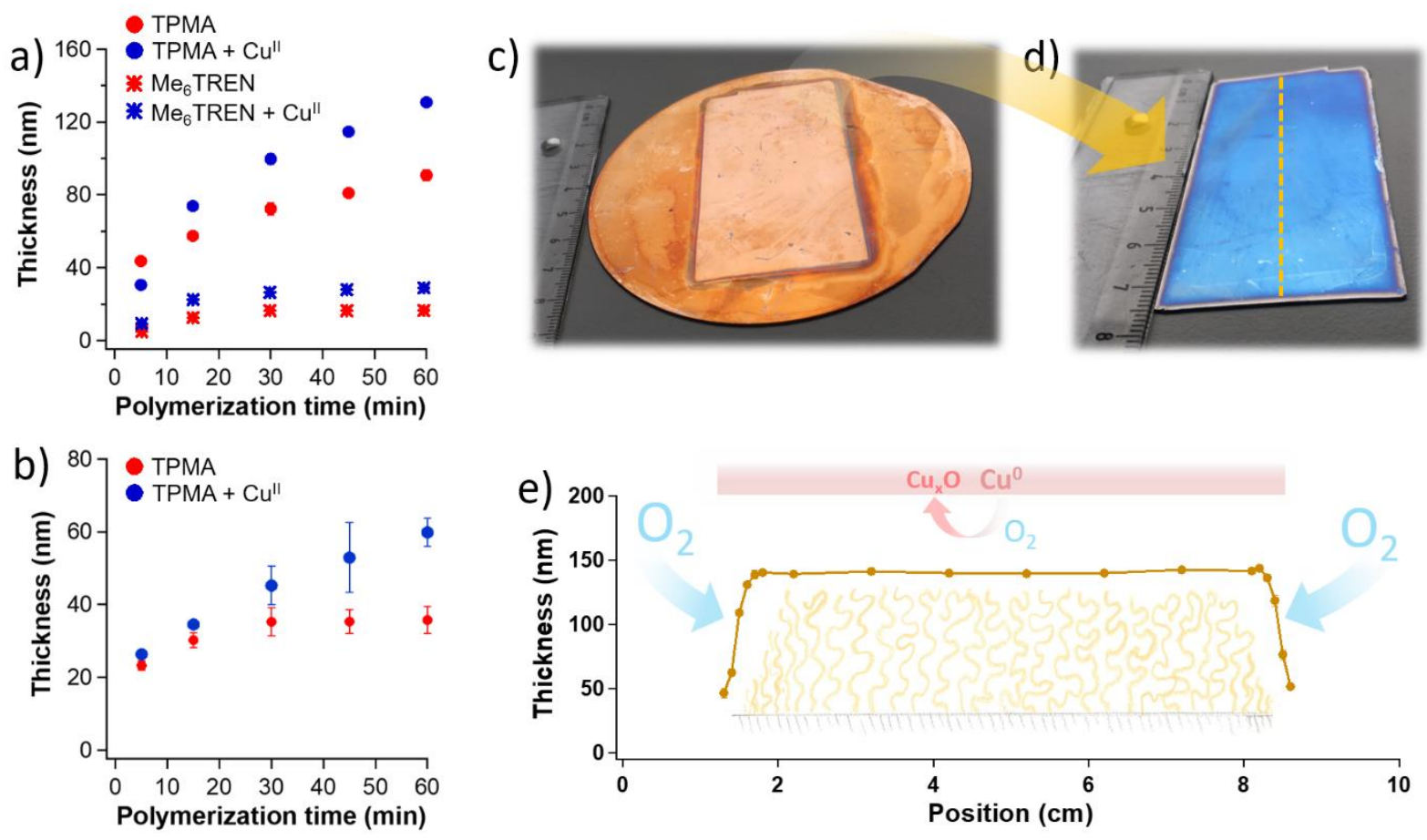

Figure 1. (a) POEGMA brush thickness measured by ex situ VASE during $\mathrm{Cu}^{0}$ SI-ATRP performed without deoxygenation. The polymerization mixtures included OEGMA $(50 \% \mathrm{v} / \mathrm{v})$ in DMSO, and $16 \mathrm{mM}$ TPMA (red markers); OEGMA (50\% v/v) in DMSO, $16 \mathrm{mM}$ TPMA, and $11 \mathrm{mM} \mathrm{CuBr}_{2}$ (blue markers). Similar polymerizations were conducted with $\mathrm{Me}_{6}$ TREN $(16 \mathrm{mM})$ as ligand, with (blue markers) and without $11 \mathrm{mM} \mathrm{CuBr} 2$ (red markers). (b) PMMA brush thickness measured by ex-situ VASE during $\mathrm{Cu}^{0}$ SI-ATRP. The polymerization mixtures included MMA (50\% v/v) in DMSO, and $16 \mathrm{mM}$ TPMA (red markers); MMA (50\% v/v) in DMSO, $16 \mathrm{mM}$ TPMA, and $11 \mathrm{mM} \mathrm{CuBr}_{2}$ (blue markers). (c,d) $\mathrm{Cu}^{0}$ SI-ATRP of OEGMA was performed on $\sim 30 \mathrm{~cm}^{2}$ substrates generating relatively thick and uniform brush layers. (e) POEGMA brush dry thickness measured by VASE across the yellow dashed line highlighted in $(\mathrm{d})$.

When $11 \mathrm{mM} \mathrm{Cu}^{\mathrm{II}}$ was added to the polymerization mixture, the growth rates of POEGMA and PMMA brushes significantly increased, leading to the formation of $131 \pm 2$ and $60 \pm 4 \mathrm{~nm}$ thick brushes, respectively. The observed increment in brush-growth rates was clearly correlated to the dual functions of the externally added $\mathrm{Cu}^{\mathrm{II}}$ species. An increase in the amount of deactivator, beyond the small concentration of $\mathrm{Cu}^{\mathrm{II}}$ determined by the ATRP equilibrium, suppresses irreversible termination reactions between propagating grafts, leading to more efficient brush growth. ${ }^{23}$ Under these conditions, and after just 5 minutes of reaction, $\mathrm{Cu}^{0} \mathrm{SI}-$ ATRP provided PMMA brushes with a number-average molar mass of $38 \mathrm{kDa}$ and $Ð=1.1$ (corresponding to an average grafting density $\sigma=0.22$ chains $\mathrm{nm}^{-2}$ ). 
Furthermore, the addition of $\mathrm{Cu}^{\mathrm{II}}$ species to the polymerization mixture influenced the concentration of $\mathrm{Cu}$-based activators, which are continuously generated through comproportionation reactions with $\mathrm{Cu}^{0}$ from the copper surface (Scheme 1b). ${ }^{24}$ This phenomenon could be monitored in situ by quartz crystal microbalance with dissipation (QCMD), subjecting a $\mathrm{Cu}^{0}$-coated sensor to the same reaction mixtures used during $\mathrm{Cu}^{0}$ SI-ATRP, and simultaneously recording the mass variation of the metal layer with time (Figure 2a). Increasing the concentration of externally added $\mathrm{Cu}^{\mathrm{II}}$ within the range $0-35 \mathrm{mM}$, while maintaining a fixed concentration of TPMA $(40 \mathrm{mM})$, led to a progressive increment in the amount of $\mathrm{Cu}$ species desorbed from the metallic plate (Figure $2 \mathrm{~b}$ ), which were presumably mainly constituted of $\mathrm{Cu}^{\mathrm{I}}$ adducts generated by comproportionation.
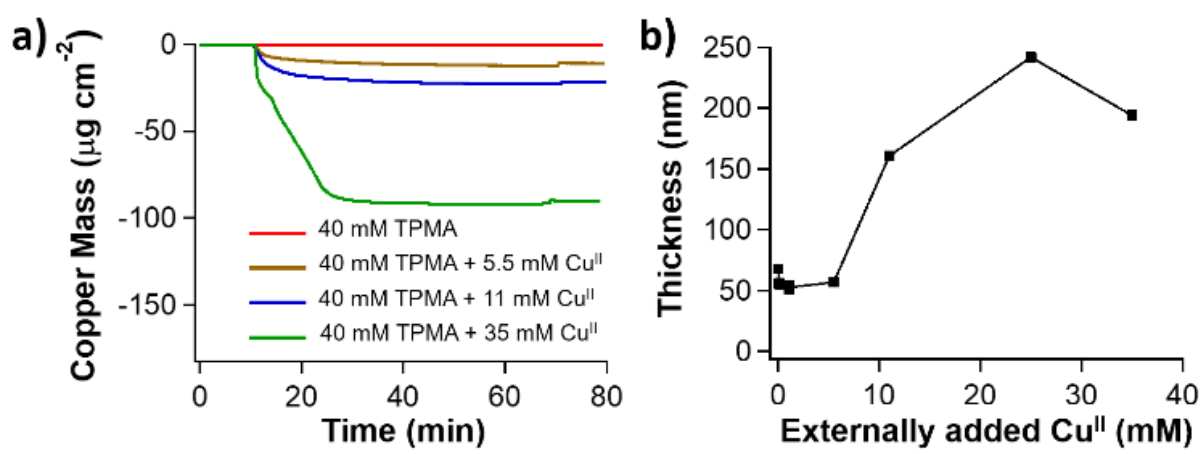

Figure 2. (a) Mass of copper species desorbed from a $\mathrm{Cu}^{0}$-coated QCM-D sensor subjected to different polymerization mixtures. (b) POEGMA brush thicknesses measured by VASE after 60 minutes of $\mathrm{Cu}^{0}$ SI-ATRP performed with different initial concentrations of $\mathrm{CuBr}_{2}$ and a fixed content of TPMA (40 mM).

In support of this hypothesis, the thickness of POEGMA brushes obtained after 60 minutes of polymerization progressively increased with the concentration of added $\mathrm{Cu}^{\mathrm{II}}$, reaching a maximum of $242 \pm 2 \mathrm{~nm}$ for $25 \mathrm{mM}$ of added $\mathrm{Cu}^{\mathrm{II}}$ (Figure $2 \mathrm{c}$ ). A further addition of $\mathrm{Cu}^{\mathrm{II}} \mathrm{did}$ not translate into an increment in brush thickness, which decreased by nearly $20 \%(194 \pm 2$ $\mathrm{nm}$ ) when $\mathrm{Cu}^{\mathrm{II}}$ concentration reached $35 \mathrm{mM}$ (Figure 2c). Besides shifting the equilibrium of comproportionation towards the formation of $\mathrm{Cu}^{\mathrm{I}}$-based species, inducing an increment in both 
polymerization rate and brush thickness, $\mathrm{Cu}^{\mathrm{II}}$ adducts intrinsically act as deactivators during $\mathrm{Cu}^{0}$ SI-ATRP. The balance between these two roles, i.e. favouring the formation of activator, as well as acting as deactivator, is highly dependent on the concentration of $\mathrm{Cu}^{\mathrm{II}}$ initially added to the reaction mixture. ${ }^{25}$

The central role of copper comproportionation in determining the polymerization kinetics was confirmed by comparing $\mathrm{Cu}^{0}$ SI-ATRP of OEGMA employing TPMA and tris[2(dimethylamino)ethyl]amine (Me6TREN), the latter ligand providing higher ATRP activity but a slower rate of comproportionation in DMSO. ${ }^{26}$ The growth of POEGMA brushes was remarkably slower when Me6TREN was used (Figure 1a), and POEGMA-brush thicknesses could not exceed $30 \mathrm{~nm}$ even after 60 minutes of reaction.

The consumption of oxygen appeared homogeneous even across extremely large substrates, with the exception of the areas close to their edges (Figure 1d-e and Figure 3a-b), where air diffused from the surrounding environment and locally terminated the polymerization. In this way, extremely uniform, $150 \mathrm{~nm}$-thick POEGMA brushes could be synthesized from $10 \mathrm{~cm}$ diameter wafers on a lab bench, after just 1 hour of polymerization (Figure 3a).

The tolerance towards oxygen by $\mathrm{Cu}^{0}$ SI-ATRP is reminiscent of that recently reported by Anastasaki and Haddleton, when ATRP in the presence of $\mathrm{Cu}^{0}$ was performed in solution while removing the headspace of the reaction vessel. ${ }^{17}$ However, besides the presence of $\mathrm{Cu}^{0}$, an excess of alkyl halide initiator was previously identified as a requisite to rapidly consume oxygen within the reaction medium. In contrast, the addition of $60 \mathrm{mM}$ ethyl $\alpha$ bromoisobutyrate $(\mathrm{EBIB})$ during $\mathrm{Cu}^{0}$ SI-ATRP significantly slowed down the growth of polymer brushes (Figure 3c-d). This was presumably due to the fast conversion of monomer within the small volume of solution overlying the initiator-bearing substrate, which limited the achievable molecular weight of the brushes, and simultaneously led a substantial increase in the viscosity of the reaction mixture. In addition, the presence of EBIB both consumed $\mathrm{Cu}^{\mathrm{I}}$ and 
slowed down its diffusion from the $\mathrm{Cu}^{0}$ plate due to the polymerization occurring in the interstitial solution.
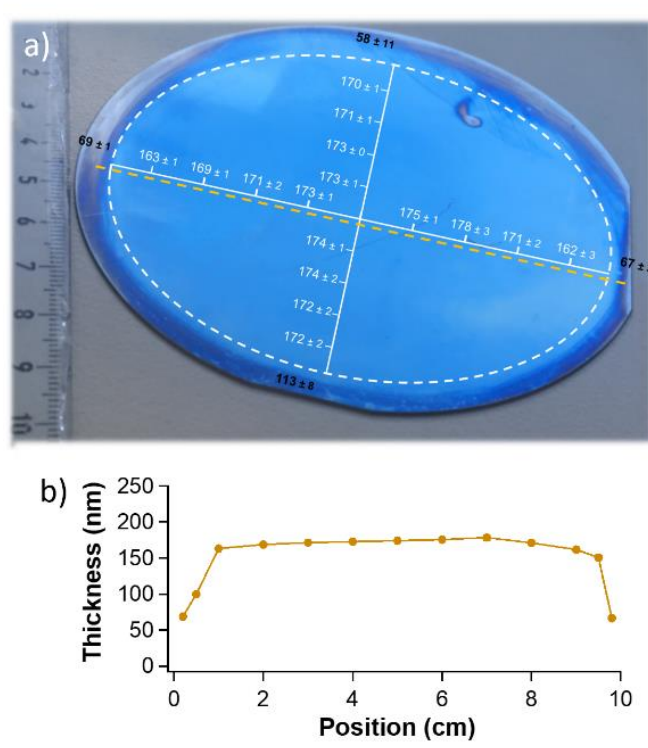
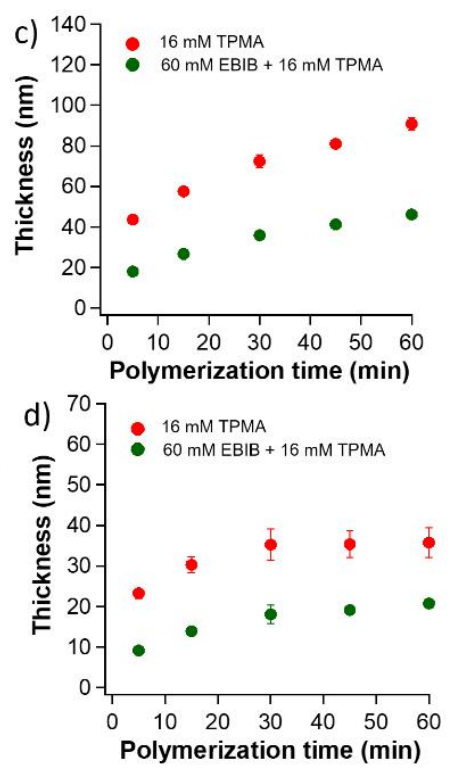
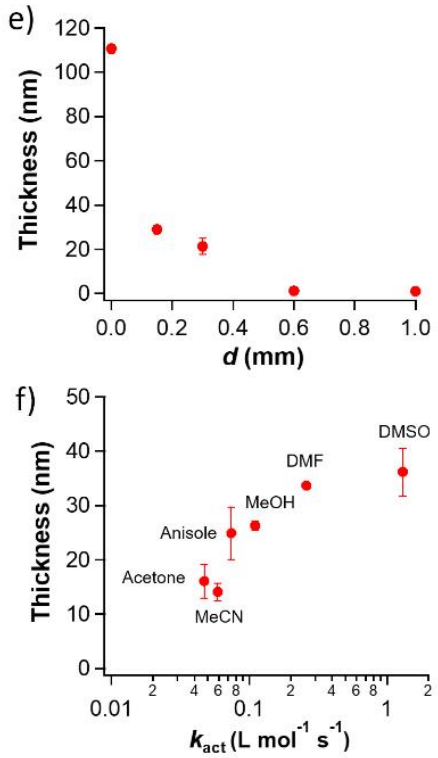

Figure 3. (a) POEGMA bushes synthesized by $\mathrm{Cu}^{0}$ SI-ATRP under environmental conditions from a $10 \mathrm{~cm}$ diameter, ATRP-initiator-functionalized silicon wafer. The values of brush thickness (indicated in white) were measured across the whole wafer by VASE. The brush thickness at the edges was highlighted in black. (b) Brush thicknesses measured along the POEGMA-coated silicon wafer by VASE; the thickness values were measured along the dashed yellow line highlighted in (a). (c) POEGMA brush thickness measured by ex-situ VASE during $\mathrm{Cu}^{0}$ SI-ATRP performed without deoxygenation. The polymerization mixtures included OEGMA (50\% v/v) in DMSO, and $16 \mathrm{mM}$ TPMA (red markers); OEGMA $(50 \% \mathrm{v} / \mathrm{v})$ in DMSO, $16 \mathrm{mM}$ TPMA, and $60 \mathrm{mM}$ EBIB (green markers). (d) PMMA brush thickness measured by ex-situ VASE during $\mathrm{Cu}^{0}$ SI-ATRP. The polymerization mixtures included MMA $(50 \% \mathrm{v} / \mathrm{v})$ in DMSO, and $16 \mathrm{mM}$ TPMA (red markers); MMA (50\% v/v) in DMSO, $16 \mathrm{mM}$ TPMA, and $60 \mathrm{mM}$ EBIB (green markers). (e) POEGMA brush thickness measured by VASE after 60 minutes of $\mathrm{Cu}^{0}$ SI-ATRP performed at different $d$ values; the polymerization mixtures include OEGMA (50\% v/v) in DMSO, $16 \mathrm{mM}$ TPMA and $5.5 \mathrm{mM} \mathrm{CuBr}$. (f) PMMA brush thickness measured by VASE after 60 minutes of $\mathrm{Cu}^{0}$ SI-ATRP performed in solvents showing a different rate constant of activation ( $k_{\text {act}}$, measured for mixtures including $\mathrm{CuBr}$, 1,1,4,7,10,10-hexamethyltriethylenetetramine, EBIB). ${ }^{27}$ The polymerization mixtures included $16 \mathrm{mM}$ TPMA, $11 \mathrm{mM} \mathrm{CuBr}$, and MMA (50\% v/v) in acetonitrile (MeCN), acetone, anisole, methanol $(\mathrm{MeOH})$, dimethylformamide (DMF) and DMSO.

In $\mathrm{Cu}^{0} \mathrm{SI}-\mathrm{ATRP}$, the distance between the initiator-bearing substrate and the copper plate $(d)$ represents the main factor determining the oxygen tolerance of the grafting process. As 
displayed in Figure 3e, when $d \sim 10 \mu \mathrm{m}$ the thickness of POEGMA brushes reached $110 \pm 1$ $\mathrm{nm}$ after 60 minutes of polymerization. An increase in $d$ caused a concomitant increment in the area of the gas-liquid interface at the edges of oppositely facing surfaces, favouring the diffusion of oxygen from the surrounding environment. When $d>0.6 \mathrm{~mm}$, no brush growth was recorded (brush thickness $\leq 1.5 \mathrm{~nm}$ ), as the amount of oxygen diffusing into the polymerization medium from the atmosphere was likely exceeding that consumed by $\mathrm{Cu}^{0}$.

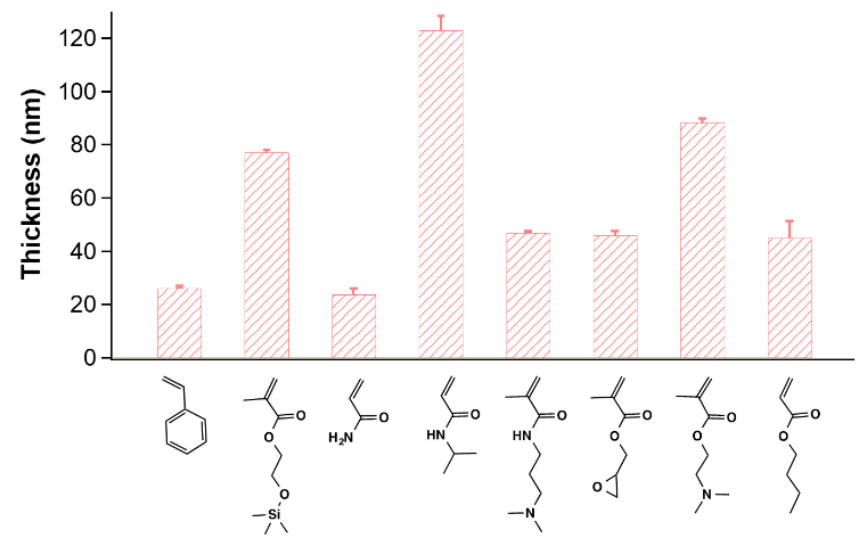

Figure 4. Brush thickness measured by VASE after 60 minutes of $\mathrm{Cu}^{0}$ SI-ATRP performed with different monomers (using $16 \mathrm{mM}$ TPMA, and $11 \mathrm{mM} \mathrm{CuBr}$ ). These include styrene $(50 \% \mathrm{v} / \mathrm{v}$ in anisole), 2-(trimethylsilyloxy)ethyl methacrylate (HEMATMS) $(50 \% \mathrm{v} / \mathrm{v}$ in DMSO), acrylamide (3 M in DMSO), NIPAM (3 M in DMSO), 3-(dimethylamino)propyl methacrylamide (DMAPMA) (3 M in DMSO), glycidyl methacrylate (GMA) $(50 \% \mathrm{v} / \mathrm{v}$ in DMSO), 2-(dimethylamino)ethyl methacrylate (DMAEMA) (50\% v/v in DMSO), and butyl acrylate (BA) (50\% v/v in DMSO).

Similarly to what was previously observed for homogeneous ATRP in solution, ${ }^{28}$ the "polarity" of the solvent, (Supporting Information), ${ }^{29}$ additionally influenced the synthesis of brushes by $\mathrm{Cu}^{0}$ SI-ATRP. In particular, the thickness of POEGMA brushes obtained after 60 minutes of polymerization in different media increased with the corresponding activation rate constant of ATRP $\left(k_{\text {act }}\right)$, the thickest films could be synthesized in the most polar organic solvents amongst those studied, i.e. DMSO and dimethylformamide (DMF) (Figure $3 f$ and Figure $\mathrm{S} 2$ ), while $\mathrm{Cu}^{0}$ SI-ATRP in water showed an uncontrolled character (Figure S3).

Using DMSO as solvent and TPMA as ligand, $\mathrm{Cu}^{0}$ SI-ATRP could be thus applied to a large variety of monomers, enabling the polymerization of acrylates, methacrylates, acrylamides and 
styrene (Figure 4). Remarkably, in all these cases, relatively high brush thicknesses were obtained in just 1 hour of polymerization, while applying the same ligand and $\mathrm{Cu}^{\mathrm{II}}$ concentration (Figure 3b).

Overall, these results demonstrate that, under optimized reaction conditions, $\mathrm{Cu}^{0}$ SI-ATRP enables the highly controlled synthesis of compositionally different, thick brushes in short reaction times, over extremely large areas and without the need for degassing the monomer mixtures or carrying out the reaction in the presence of an inert atmosphere. These highly attractive features, revealed through a comprehensive understanding of its mechanism, make oxygen-tolerant $\mathrm{Cu}^{0}$ SI-ATRP a very promising method for translating surface-initiated polymerization from fundamental, academic studies, to technologically relevant applications, including the fabrication of hybrid coatings, ${ }^{30-32}$ biosensors, ${ }^{33-35}$ cell-culture platforms ${ }^{36-41}$ and lubricating films. ${ }^{42,43}$

\section{Associated Content}

Experimental procedures are included in the supplementary information.

\section{Author Information}

Corresponding Authors:

*Email: nicholas.spencer@,mat.ethz.ch

*Email: matyjaszewski@,cmu.edu

*Email: edmondo.benetti@mat.ethz.ch

\section{Acknowledgments}


This work was financially supported by European Union's Horizon 2020 research and innovation program (grant agreement No 669562) and the Swiss National Science Foundation (SNSF “Ambizione” PZ00P2-790 148156).

\section{Competing interests}

The authors declare no competing interests.

\section{References}

1. Yeow, J.; Chapman, R.; Gormley, A. J.; Boyer, C., Up in the air: oxygen tolerance in controlled/living radical polymerisation. Chem. Soc. Rev. 2018, 47, 4357-4387.

2. $\quad$ Li, M.; Fromel, M.; Ranaweera, D.; Rocha, S.; Boyer, C.; Pester, C. W., SI-PET-RAFT: Surface-Initiated Photoinduced Electron Transfer-Reversible Addition-Fragmentation Chain Transfer Polymerization. ACS Macro Lett. 2019, 8, 374-380.

3. Barbey, R.; Lavanant, L.; Paripovic, D.; Schuwer, N.; Sugnaux, C.; Tugulu, S.; Klok, H. A., Polymer Brushes via Surface-Initiated Controlled Radical Polymerization: Synthesis, Characterization, Properties, and Applications. Chem. Rev. 2009, 109, 5437 5527.

4. Zoppe, J. O.; Ataman, N. C.; Mocny, P.; Wang, J.; Moraes, J.; Klok, H. A., SurfaceInitiated Controlled Radical Polymerization: State-of-the-Art, Opportunities, and Challenges in Surface and Interface Engineering with Polymer Brushes Chem. Rev. 2017, 117, 4667-4667.

5. Matyjaszewski, K.; Miller, P. J.; Shukla, N.; Immaraporn, B.; Gelman, A.; Luokala, B. B.; Siclovan, T. M.; Kickelbick, G.; Vallant, T.; Hoffmann, H.; Pakula, T., Polymers at interfaces: Using atom transfer radical polymerization in the controlled growth of 
homopolymers and block copolymers from silicon surfaces in the absence of untethered sacrificial initiator. Macromolecules 1999, 32, 8716-8724.

6. Matyjaszewski, K.; Dong, H. C.; Jakubowski, W.; Pietrasik, J.; Kusumo, A., Grafting from surfaces for "Everyone": ARGET ATRP in the presence of air. Langmuir 2007, $23,4528-4531$.

7. Dunderdale, G. J.; Urata, C.; Miranda, D. F.; Hozumi, A., Large-Scale and Environmentally Friendly Synthesis of pH-Responsive Oil-Repellent Polymer Brush Surfaces under Ambient Conditions. ACS Appl. Mater. Interfaces 2014, 6, 1186411868.

8. Dunderdale, G. J.; England, M. W.; Urata, C.; Hozumi, A., Polymer Brush Surfaces Showing Superhydrophobicity and Air-Bubble Repellency in a Variety of Organic Liquids. ACS Appl. Mater. Interfaces 2015, 7, 12220-12229.

9. Min, K.; Jakubowski, W.; Matyjaszewski, K., AGET ATRP in the presence of air in miniemulsion and in bulk. Macromol. Rapid Commun. 2006, 27, 594-598.

10. Sato, T.; Dunderdale, G. J.; Urata, C.; Hozumi, A., Sol-Gel Preparation of Initiator Layers for Surface-Initiated ATRP: Large-Scale Formation of Polymer Brushes Is Not a Dream. Macromolecules 2018, 51, 10065-10073.

11. Navarro, L. A.; Enciso, A. E.; Matyjaszewski, K.; Zauscher, S., Enzymatically Degassed Surface-Initiated Atom Transfer Radical Polymerization with Real-Time Monitoring. J. Am. Chem. Soc. 2019, 141, 3100-3109.

12. Enciso, A. E.; Fu, L. Y.; Russell, A. J.; Matyjaszewski, K., A Breathing Atom-Transfer Radical Polymerization: Fully Oxygen-Tolerant Polymerization Inspired by Aerobic Respiration of Cells. Angew. Chem. Int. Edit. 2018, 57, 933-936.

13. Narupai, B.; Page, Z. A.; Treat, N. J.; McGrath, A. J.; Pester, C. W.; Discekici, E. H.; Dolinski, N. D.; Meyers, G. F.; de Alaniz, J. R.; Hawker, C. J., Simultaneous 
Preparation of Multiple Polymer Brushes under Ambient Conditions using Microliter Volumes. Angew. Chem. Int. Edit. 2018, 57, 13433-13438.

14. Matyjaszewski, K.; Tsarevsky, N. V.; Braunecker, W. A.; Dong, H.; Huang, J.; Jakubowski, W.; Kwak, Y.; Nicolay, R.; Tang, W.; Yoon, J. A., Role of $\mathrm{Cu}^{0}$ in Controlled/“Living” Radical Polymerization. Macromolecules 2007, 40, 7795-7806.

15. Matyjaszewski, K.; Coca, S.; Gaynor, S. G.; Wei, M.; Woodworth, B. E., Zerovalent Metals in Controlled/“Living” Radical Polymerization. Macromolecules 1997, 30, 7348-7350.

16. Boyer, C.; Corrigan, N. A.; Jung, K.; Nguyen, D.; Nguyen, T. K.; Adnan, N. N. M.; Oliver, S.; Shanmugam, S.; Yeow, J., Copper-Mediated Living Radical Polymerization (Atom Transfer Radical Polymerization and Copper(0) Mediated Polymerization): From Fundamentals to Bioapplications. Chem. Rev. 2016, 116, 1803-1949.

17. Liarou, E.; Whitfield, R.; Anastasaki, A.; Engelis, N. G.; Jones, G. R.; Velonia, K.; Haddleton, D. M., Copper-Mediated Polymerization without External Deoxygenation or Oxygen Scavengers. Angew. Chem. Int. Edit. 2018, 57, 8998-9002.

18. Che, Y. J.; Zhang, T.; Du, Y. H.; Amin, I.; Marschelke, C.; Jordan, R., "On Water" Surface-initiated Polymerization of Hydrophobic Monomers. Angew. Chem. Int. Edit. 2018, $57,16380-16384$.

19. Zhang, T.; Du, Y. H.; Kalbacova, J.; Schubel, R.; Rodriguez, R. D.; Chen, T.; Zahn, D. R. T.; Jordan, R., Wafer-scale synthesis of defined polymer brushes under ambient conditions. Polym. Chem. 2015, 6, 8176-8183.

20. Zhang, T.; Du, Y.; Muller, F.; Amin, I.; Jordan, R., Surface-initiated $\mathrm{Cu}(0)$ mediated controlled radical polymerization (SI-CuCRP) using a copper plate. Polym. Chem. 2015, 6, 2726-2733. 
21. Dehghani, E. S.; Du, Y.; Zhang, T.; Ramakrishna, S. N.; Spencer, N. D.; Jordan, R.; Benetti, E. M., Fabrication and Interfacial Properties of Polymer Brush Gradients by Surface-Initiated $\mathrm{Cu}(0)$-Mediated Controlled Radical Polymerization. Macromolecules 2017, 50, 2436-2446.

22. Fantin, M.; Ramakrishna, S. N.; Yan, J. J.; Yan, W. Q.; Divandari, M.; Spencer, N. D.; Matyjaszewski, K.; Benetti, E. M., The Role of $\mathrm{Cu}^{0}$ in Surface-Initiated Atom Transfer Radical Polymerization: Tuning Catalyst Dissolution for Tailoring Polymer Interfaces. Macromolecules 2018, 51, 6825-6835.

23. Benetti, E. M.; Kang, C. J.; Mandal, J.; Divandari, M.; Spencer, N. D., Modulation of Surface-Initiated ATRP by Confinement: Mechanism and Applications. Macromolecules 2017, 50, 5711-5718.

24. Konkolewicz, D.; Wang, Y.; Zhong, M. J.; Krys, P.; Isse, A. A.; Gennaro, A.; Matyjaszewski, K., Reversible-Deactivation Radical Polymerization in the Presence of Metallic Copper. A Critical Assessment of the SARA ATRP and SET-LRP Mechanisms. Macromolecules 2013, 46, 8749-8772.

25. Zhang, Y. Z.; Wang, Y.; Peng, C. H.; Zhong, M. J.; Zhu, W. P.; Konkolewicz, D.; Matyjaszewski, K., Copper-Mediated CRP of Methyl Acrylate in the Presence of Metallic Copper: Effect of Ligand Structure on Reaction Kinetics. Macromolecules 2012, $45,78-86$.

26. Ribelli, T. G.; Krys, P.; Cong, Y.; Matyjaszewski, K., Model Studies of Alkyl Halide Activation and Comproportionation Relevant to RDRP in the Presence of $\mathrm{Cu} 0$. Macromolecules 2015, 48, 8428-8436.

27. Braunecker, W. A.; Tsarevsky, N. V.; Gennaro, A.; Matyjaszewski, K., Thermodynamic Components of the Atom Transfer Radical Polymerization Equilibrium: Quantifying Solvent Effects. Macromolecules 2009, 42, 6348-6360. 
28. Horn, M.; Matyjaszewski, K., Solvent Effects on the Activation Rate Constant in Atom Transfer Radical Polymerization. Macromolecules 2013, 46, 3350-3357.

29. Kamlet, M. J.; Abboud, J. L. M.; Abraham, M. H.; Taft, R. W., Linear Solvation Energy Relationships .23. A Comprehensive Collection of the Solvatochromic Parameters, PiStar, Alpha and Beta, and Some Methods for Simplifying the Generalized Solvatochromic Equation. J. Org. Chem. 1983, 48, 2877-2887.

30. Christau, S.; Moller, T.; Yenice, Z.; Genzer, J.; von Klitzing, R., Brush/Gold Nanoparticle Hybrids: Effect of Grafting Density on the Particle Uptake and Distribution within Weak Polyelectrolyte Brushes. Langmuir 2014, 30, 13033-13041.

31. Christau, S.; Moller, T.; Brose, F.; Genzer, J.; Soltwedel, O.; von Klitzing, R., Effect of gold nanoparticle hydrophobicity on thermally induced color change of PNIPAM brush/gold nanoparticle hybrids. Polymer 2016, 98, 454-463.

32. Christau, S.; Moeller, T.; Genzer, J.; Koehler, R.; von Klitzing, R., Salt-Induced Aggregation of Negatively Charged Gold Nanoparticles Confined in a Polymer Brush Matrix. Macromolecules 2017, 50, 7333-7343.

33. Joh, D. Y.; Hucknall, A. M.; Wei, Q. S.; Mason, K. A.; Lund, M. L.; Fontes, C. M.; Hill, R. T.; Blair, R.; Zimmers, Z.; Achar, R. K.; Tseng, D.; Gordan, R.; Freemark, M.; Ozcan, A.; Chilkoti, A., Inkjet-printed point-of-care immunoassay on a nanoscale polymer brush enables subpicomolar detection of analytes in blood. Proc. Natl. Acad. Sci. U.S.A. 2017, 114, E7054-E7062.

34. Fortin, N.; Klok, H. A., Glucose Monitoring Using a Polymer Brush Modified Polypropylene Hollow Fiber-based Hydraulic Flow Sensor. ACS Appl. Mater. Interfaces 2015, 7, 4631-4640. 
35. Badoux, M.; Billing, M.; Klok, H. A., Polymer brush interfaces for protein biosensing prepared by surface-initiated controlled radical polymerization. Polym. Chem. 2019, 10, $2925-2951$

36. Paripovic, D.; Hall-Bozic, H.; Klok, H. A., Osteoconductive surfaces generated from peptide functionalized poly(2-hydroxyethyl methacrylate-co-2-

(methacryloyloxy)ethyl phosphate) brushes. J. Mater. Chem. 2012, 22, 19570-19578.

37. Desseaux, S.; Klok, H. A., Temperature-Controlled Masking/Unmasking of CellAdhesive Cues with Poly(ethylene glycol) Methacrylate Based Brushes.

Biomacromolecules 2014, 15, 3859-3865.

38. Bhat, R. R.; Chaney, B. N.; Rowley, J.; Liebmann-Vinson, A.; Genzer, J., Tailoring cell adhesion using surface-grafted polymer gradient assemblies. Adv. Mater. 2005, $17,2802-2807$.

39. Klein Gunnewiek, M.; Di Luca, A.; Bollemaat, H. Z.; van Blitterswijk, C. A.; Vancso, G. J.; Moroni, L.; Benetti, E. M., Creeping Proteins in Microporous Structures: Polymer Brush-Assisted Fabrication of 3D Gradients for Tissue Engineering. Adv. Health. Mater. 2015, 4, 1169-1174.

40. Lilge, I.; Schonherr, H., Block Copolymer Brushes for Completely Decoupled Control of Determinants of Cell-Surface Interactions. Angew. Chem. Int. Edit. 2016, 55, 13114-13117.

41. Dou, X. Q.; Li, P.; Jiang, S. Y.; Bayat, H.; Schonherr, H., Bioinspired Hierarchically Structured Surfaces for Efficient Capture and Release of Circulating Tumor Cells. ACS Appl. Mater. Interfaces 2017, 9, 8508-8518.

42. Chen, M.; Briscoe, W. H.; Armes, S. P.; Klein, J., Lubrication at Physiological Pressures by Polyzwitterionic Brushes. Science 2009, 323, 1698-1701. 
43. Li, A.; Benetti, E. M.; Tranchida, D.; Clasohm, J. N.; Schonherr, H.; Spencer, N. D., Surface-Grafted, Covalently Cross-Linked Hydrogel Brushes with Tunable Interfacial and Bulk Properties. Macromolecules 2011, 44, 5344-5351. 
For Table of Contents Use Only:

Translating Surface-Initiated Atom Transfer Radical Polymerization into Technology: The Mechanism of $\mathrm{Cu}^{0}$-Mediated SI-ATRP under Environmental Conditions

Wenqing Yan, Marco Fantin, Nicholas D. Spencer, Krzysztof Matyjaszewski, Edmondo M.

Benetti

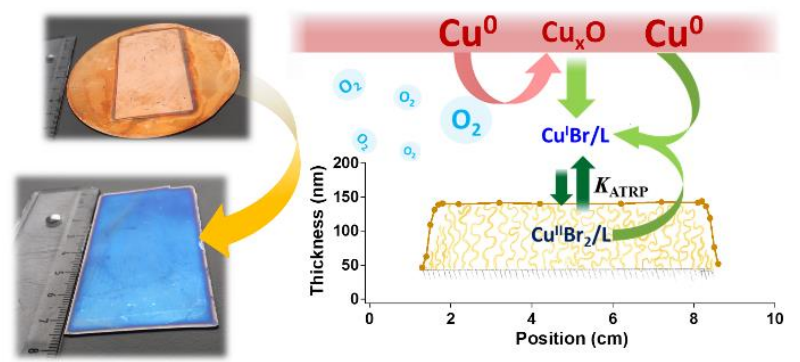

